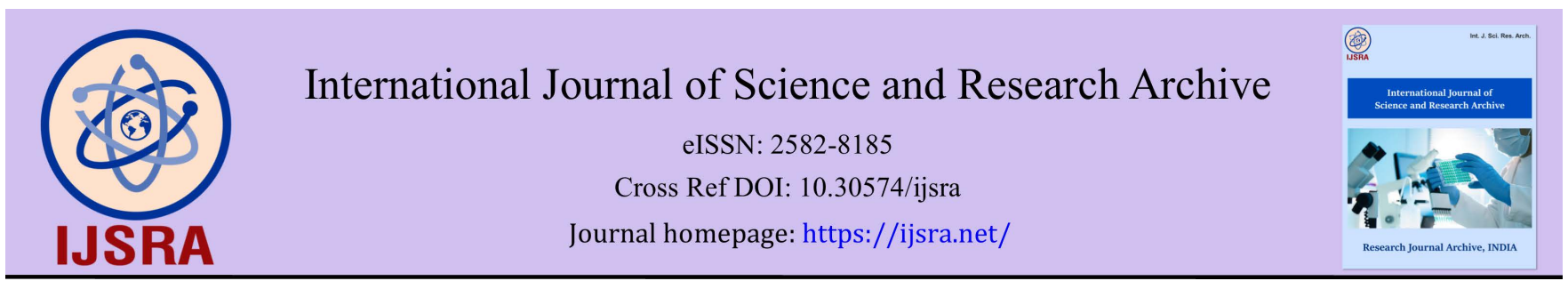

(RESEARCH ARTiClE)

\title{
Study on the factors influencing adherence to daily exercise in elderly peoples of Dhaka city: A cross sectional survey-based study
}

\author{
A.K.M. Rezwan ${ }^{1,}{ }^{*}$, Uttam Kumar Das 1, Ekramul Hasan 2, Dolan Chapa Lucky ${ }^{3}$ \\ ${ }^{1}$ Senior Lecturer of physiotherapy: Gono Bishwabidyalay. Saver, Dhaka. \\ 2 Physiotherapy Consultant: Aichi Hospital Limited, Uttara, Dhaka. \\ 3 Intern physiotherapist: Gono Bishwabidyalay.
}

International Journal of Science and Research Archive, 2022, 05(01), 022-027

Publication history: Received on 18 December 2021; revised on 26 January 2022; accepted on 28 January 2022

Article DOI: https://doi.org/10.30574/ijsra.2022.5.1.0029

\begin{abstract}
Background: Adherence of exercise and physical activity leads to long term physical problems. Objective: The objective of the study was to identify factors leading to adherence to daily exercise among elderly people of the city of Dhaka.

Methodology \& Materials: It was a cross-sectional study conducted among the elderly population of Dhaka city at one point in time. According to the inclusion and exclusion criteria, 120 respondents were randomly selected. A pretested, modified semi structured questionnaire was used to collect the data.

Result: According to our study, the mean age of the respondents was $71.69 \pm 4.052$ years, with a range of $65-75$ years and above. The male to female ration was about equal (56.7\%). The poor (33.3\%) and lower middle class $(28.3 \%)$ respondents were more likely to engage in daily exercise. Nearly half of the respondents were a higher secondary pass and a housewife who adhered to regular exercise. Near about $61.7 \%$ of the respondents were not given data regarding daily exercise while $45 \%$ avoid daily exercise as a result of physical discomfort. The presence of family demotivation also contributes to adherence to exercise, as about $27 \%$ of respondents reported being demotivated from daily exercise and $73 \%$ reported being committed to daily exercise. Laziness was also associated with adherence to exercise, as $80 \%$ reported skipping daily exercise. Physical illness is most common cause of adherence to exercise regularly near about $71.7 \%$ felt this problem. Different types of disease condition lead to adherence to exercise like joint pain, weakness, breathlessness, palpitations, and weakness. $31.7 \%$ of respondents felt adherent to daily exercise due to joint pain, whereas $1.7 \%$ were adherent to daily exercise due to physical impairment. Approximately $33.3 \%$ of the respondents considered adherence to daily exercise to be influenced by their exercise environment. In general, $66.7 \%$ of the respondents do not continue regular exercise because of a lack of adequate exercise fields. $20 \%$ of the respondents get up early in the morning and exercise regularly. The majority of respondents, $80 \%$, did not do regular exercise due to this problem. Regular daily long- term exercise is difficult for elderly people due to different reasons. Nearly $40 \%$ of respondents continue to exercise above 1 hour daily. In this study, there was a statistically significant association between Family Motivation and Gender, where $p=0.002$, Physical Problem with Gender, where $p=0.04$, Physical Problem with skipping of daily exercise, where $\mathrm{p}=0.042$, and Physical Problem with waking up early in the morning, where $\mathrm{p}=0.05$.
\end{abstract}

Conclusion: Physical exercise is more common in elderly due to different factors. Promoting physical exercise and encouraging daily participation may reduce adverse health outcomes.

Keywords: Adherence; Elderly; Inactivity; Daily exercise; ADL

\footnotetext{
${ }^{*}$ Corresponding author: A. K. M. Rezwan

Senior Lecturer of Physiotherapy, Gono Bishwabidyalay.
}

Copyright $(2022$ Author(s) retain the copyright of this article. This article is published under the terms of the Creative Commons Attribution Liscense 4.0. 


\section{Introduction}

Physical inactivity is a global problem, with estimates stating that one in four adults are not active enough. Physical inactivity has grave consequences, the highest risk of chronic degenerative diseases like CVD, cancer, respiratory diseases and diabetes [1]. Providing qualified geriatric care to seniors is a public health concern. Gradual loss of muscle strength associated with loss of muscle quality and reduced muscle strength resulting in decreased mobility, reduced gait speed, and changes in balance, as well as an increased risk of falling [2,3]. A regular exercise program can significantly improve balance and reduce the risk of falls among older adults, and it can also reduce the risk of cardiovascular disease, diabetes, osteoporosis, and health care costs [4, 5, 6]. Exercise and repetitive movements build physical strength and maintain fitness [7]. Regular aerobic exercise can maintain daily living activities and proper physical function of a healthy population [8]. Exercise of 15 to 100 minutes a day results in a $4 \%$ reduction in mortality from any cause [9]. The average number of older adults who exercise regularly is only 10 to 30 percent [10]. There is a particularly high prevalence of inactivity in older people, with only $10 \%$ of people over 75 years old in the UK meeting the current physical activity guidelines [11]. A key factor in promoting health and longevity is adhering to physical activity and exercise programs [12]. A significant proportion of the elderly don't engage in regular physical activity. These behaviors are influenced by their health status and system-related motivators and barriers [13]. Exercise is essential for public health; exercise has been recognized as a factor that contributes to improved health across all age groups, yet many people do not engage in regular physical activity and therefore miss the chance to benefit from these significant physical and mental health benefits $[14,15]$. The World Health Organization states that everyone should have the opportunity to enjoy healthful physical, social, and mental well-being as they age. Socioeconomic disadvantage is associated with significantly poorer health in older age and shorter life expectancy [16]. The worldwide estimated burden of disease from physical inactivity is $6 \%$ from coronary heart disease, $7 \%$ from type 2 diabetes, $10 \%$ from breast cancer, and $10 \%$ from colon cancer. Physical inactivity contributes to $9 \%$ of premature mortality worldwide.17, 18, 19]. By participating in long-term exercise, older adults will live a healthier lifestyle and need fewer health care services. It would be beneficial to understand how elderly people adhere to exercise plans and how they maintain them [20,21]

\section{Methodology}

It used a cross-sectional survey based on pretested, modified questionnaires distributed to elderly people over the age of 65 who do not regularly exercise in different areas of Dhaka city. 120 respondents, both males and females, were surveyed. All respondents provided informed consent. A non-randomized purposive sampling technique was used. A non-randomized purposive sampling technique was used. Statistical Package for Social Science (SPSS 29.0 version software Chicago) was used for data analysis, and 0.05 was set as the significant level.

\subsection{Data analysis and interpretation.}

A cross-sectional study of elderly people in different areas of Dhaka city was conducted to identify the factors influencing their adherence to daily exercise. The study involved interviewing approximately 120 respondents. Data were entered and analyzed using the statistical packages for social science (SPSS) software version 28.

Table 1 Distribution of respondents by cause of Avoidance of Daily Exercise $(n=120)$

\begin{tabular}{|l|c|c|}
\hline \multicolumn{1}{|c|}{ Cause of Avoidance } & Frequency & Percentage \\
\hline Get tired from exercise & 54 & 45.0 \\
\hline Difficult of exercises & 18 & 15.0 \\
\hline Painful exercise & 26 & 21.7 \\
\hline Felt shy to do outdoor exercises & 22 & 18.3 \\
\hline Total & 120 & 100.0 \\
\hline Mean \pm SD & & $2.13 \pm 1.185$ \\
\hline
\end{tabular}

Table 01 revealed the mean cause of avoidance of daily exercise as $2.13 \pm 1.185$. It was found that $45.0 \%, 15.0 \%, 21.7 \%$ and $18.3 \%$ of the respondents attributed the cause to avoidance of daily exercise. 


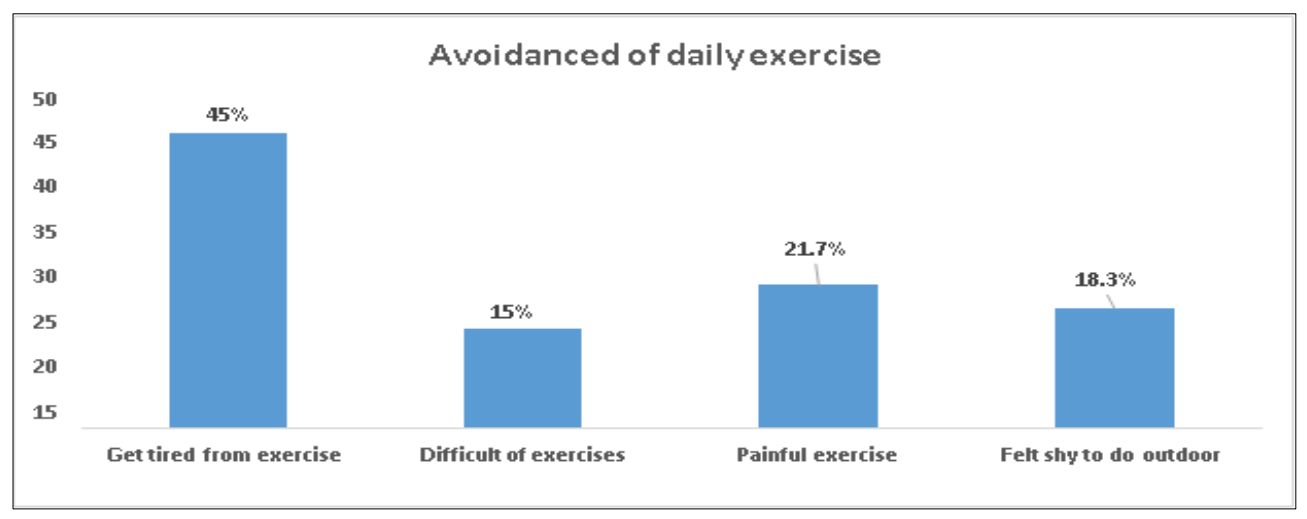

Figure 1 Distribution of respondents by cause of Avoidance of Daily Exercise

Table 2 Distribution of respondents by felt Physical problem during exercise $(n=120)$

\begin{tabular}{|l|c|c|}
\hline Name of Physical problem during exercise & Frequency & Percentage \\
\hline Pain & 38 & 31.7 \\
\hline Dizziness & 12 & 10.0 \\
\hline Breathlessness & 14 & 11.7 \\
\hline Palpitation & 10 & 8.3 \\
\hline Tiredness & 28 & 23.3 \\
\hline None & 18 & 15.0 \\
\hline Total & 120 & 100.0 \\
\hline Mean $\mathbf{E S D}$ & $\mathbf{3 . 2 7} \pm \mathbf{1 . 9 2 9}$ \\
\hline
\end{tabular}

Table-2 shows that respondents felt Physical problems during exercise on a mean of 3.27 $\pm 1.929 .31 .7 \%, 10.0 \%, 11.7 \%$, 8.3\%, 23.3\%, 15\% of the respondents suffered from Pain, Dizziness, Breathlessness, Palpitation, Tiredness, None. Exercise caused the greatest amount of pain for $80.7 \%$ of the respondents

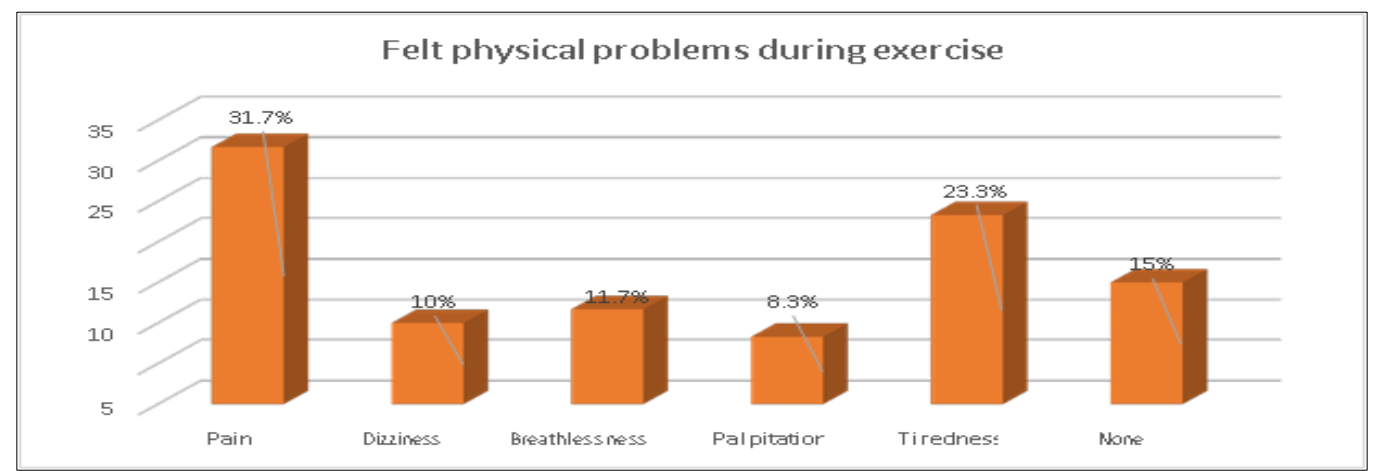

Figure 2 Distribution of respondents by felt Physical problem during exercise

As shown in table-3, the mean number of respondents with physical impairments was $1.75 \pm .913 .46 .7 \%, 36.7 \%, 15.0 \%$, $1.7 \%$ of respondents had no physical impairment, general weakness, major surgery, or impairment. There is little physical impairmentamong the respondents 
Table 3 Distribution of respondents by Physical Impairment $(n=120)$

\begin{tabular}{|l|c|c|}
\hline Physical Impairment & Frequency & Percentage \\
\hline Noimpairment & 56 & 46.7 \\
\hline General weakness & 44 & 36.7 \\
\hline Major Surgery & 18 & 15.0 \\
\hline Impaired & 2 & 1.7 \\
\hline Total & 120 & 100.0 \\
\hline Mean \pm SD & & $\mathbf{1 . 7 5} \pm . \mathbf{9 1 3}$ \\
\hline
\end{tabular}

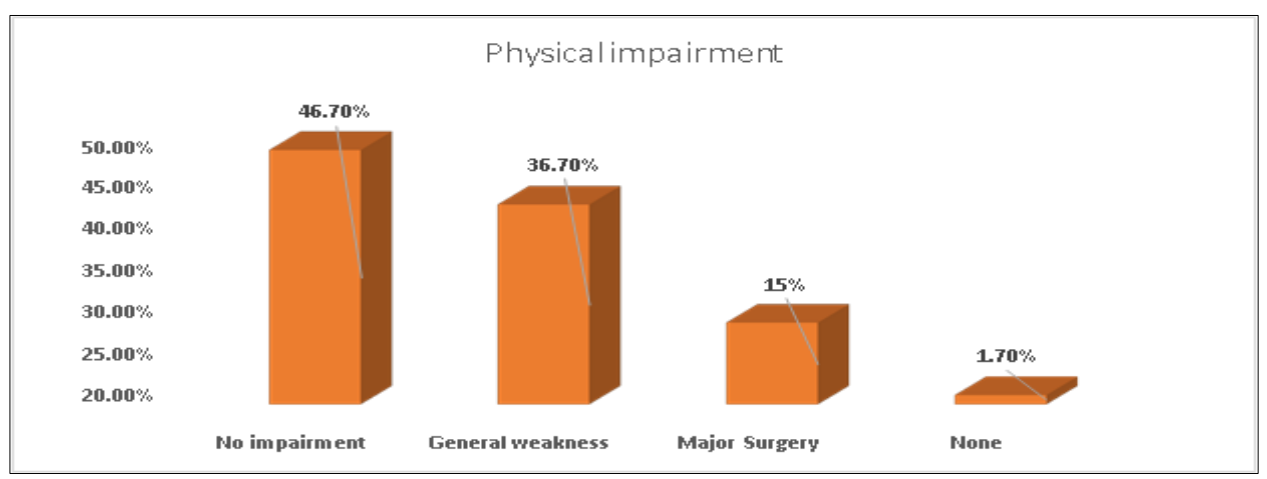

Figure 3 Distribution of respondents by Physical Impairment

\section{Discussion}

Bangladeshis are very often referred to as physically inactive. The present study aimed to investigate factors influencing elderly people's adherence to daily exercise in Dhaka. Subjects were selected based on a set of inclusive and exclusive criteria. A total of 120 subjects were selected based on the predetermined inclusive and exclusive criteria. The respondents in this study had an average age of $71.69 \pm 4.052$ years and ranged from $65-75$ years \& older. In general, older people do not agree to exercise regularly; however, in this study, the people age 70-75 years had a greater adherence to exercise day after day. This types of similarity was found by another study [22]. Male versus female ratios were close to equal, but female respondents (56.7\%) were slightly more numerous [23]. In response to the Economic and Social Research Council the poor (33.3\%) and lower middle class (28.1\%) respondents were more likely to adhere to daily physical exercise [24]. Most educated people are aware of the importance of daily exercise. According to this study, more than half of the respondents were secondary school graduates, and below SSC pass groups exercised on a daily basis more frequently. Almost $50 \%$ of housewives find it hard to exercise regularly due to their occupation. Similar findings were found in another study [25]. Daily exercise is important for good health, but about $61.7 \%$ of the respondents have not been informed about daily exercise. $45 \%$ of respondents avoided daily exercise because of physical discomfort. Another factor that contributes to adherence to exercise is demotivation from family members. About $27 \%$ of respondents were demotivated, while $73 \%$ were motivated to exercise every day. There was also a positive correlation between laziness and adherence to daily exercise, with $80 \%$ of respondents skipping regular exercise. The most common reason for not exercising regularly was physical illness, felt by about $71.7 \%$. Among different types of disease conditions such as joint pain, weakness, breathlessness, and palpitations, more respondents $(31.7 \%)$ did not continue daily exercise due to joint pain. Physical impairment was the minimum response (1,7\%) to continue regular exercise. Exercising regularly can improve your health. Those in their eighties and nineties know the importance of exercise. Approximately $33.3 \%$ of respondents believed that adherence to daily exercise is influenced by the exercise environment. For lack of proper exercise fields, more than half of the respondents $66.7 \%$ do not continue regular exercise. Maximum respondents $80 \%$ did not exercise regularly for this problem. Twenty percent of respondents wake up early and exercise regularly in the morning. Regular daily long time exercise is difficult for aging people due to different health problems, only about $40 \%$ of respondents continue regular exercise beyond one hour. In old age, people don't do regular exercise due to various kinds of burden. Their daily routine consists of watching television, spending time with family, sitting alone, participating in religious activities, and spending time on a tea stall. 
In this study, there were statistically significant associations found between Family Motivation and Gender where $\mathrm{p}$ value equal 0.002 and Physical Problem with Gender where p value equal 0.04 and Physical Problem with skipping of daily exercise where p value equal 0.042 and Physical Problem with waking up early in the morning where $p$ value equal 0.05 .

\section{Conclusion}

It was the aim of this study to examine the factors that influence older people's adherence to daily exercise. Using the current study, we can uncover some real-life adherence factors that will be helpful in helping older adults maintain adherence for a year or more. There were several factors that were related to the individual older people, such as their awareness of the health benefits of daily exercise and their family and social motivation to maintain their well-being and independence. A variety of aspects of the study were designed as physical problem, cause of inactivity, location, and adaptable exercise content. Participants can perceive that focusing on those factors will contribute to their ongoing adherence, such as family motivation, a suitable living arrangement and awareness of the benefits of daily exercise. Even so, several variables have been consistently linked with continued physical activity among the elderly, even though further research is needed.

\section{Compliance with ethical standards}

\section{Acknowledgments}

All participants provided support at every stage of the study, and the authors would like to extend their sincere gratitude to them.

\section{Disclosure of conflict of interest}

In developing the study concept, developing the study materials, and interpreting the results, all authors collaborated. RU collected and analyzed data and wrote the manuscript. A consensus on the order of presentation of the authors was reached after all authors read and approved the final version of the manuscript.

\section{References}

[1] Farrance C, Tsofliou F, Clark C. Adherence to community based group exercise interventions for older people: A mixed-methods systematic review. Prev Med. 2016; 87: 155-166.

[2] McMurdo ME, Rennie L. A controlled trial of exercise by residents of old people's homes. Age Ageing. 1993; 22(1): 11-5.

[3] Rivera Torres S, Fahey TD, Rivera MA. Adherence to Exercise Programs in Older Adults: Informative Report. Gerontol Geriatr Med. 2019; 5:

[4] Picorelli AM, Pereira DS, Felício DC, Dos Anjos DM, Pereira DA, Dias RC, Assis MG, Pereira LS. Adherence of older women with strength training and aerobic exercise. Clin Interv Aging. 2014; 14(9): 323-31.

[5] RS. Mazzeo, P Cavanagh, WJ. Evans, M Fiatarone, J Hagberg, E McAuley. Exercise and Physical Activity for Older Adults. Medicine \& Science in Sports \& Exercise. 1998; 30(6).

[6] Forkan R, Pumper B, Smyth N, Wirkkala H, Ciol MA, Shumway Cook A. Exercise adherence following physical therapy intervention in older adults with impaired balance. Phys Ther. 2006; 86(3): 401-10.

[7] CY Wang, CJ Yeh, CW Wang, CF Wang, YL Lin. The health benefits following regular ongoing exercise lifestyle in independent community dwelling older Taiwanese. Australasian Journal on Ageing. 2011; 30(1): 22-26.

[8] Hancox JE, van der Wardt V, Pollock K, Booth V, Vedhara K, Harwood RH. Factors influencing adherence to homebased strength and balance exercises among older adults with mild cognitive impairment and early dementia: Promoting Activity, Independence and Stability in Early Dementia. PLoS One. May 2019; 23; 14(5): e0217387.

[9] Sun F, Norman IJ, While AE. Physical activity in older people: a systematic review. BMC Public Health. 2013; 13: 449.

[10] Resnick B, Nigg C. Testing a theoretical model of exercise behavior for older adults. Nurs Res. 2003; 52(2):80-8. 
[11] Clarke CL, Sniehotta FF, Vadiveloo T, Argo IS, Donnan PT, McMurdo MET, Witham MD Factors associated with change in objectively measured physical activity in older people - data from the physical activity cohort Scotland study. BMC Geriatr. 2017; 17(1).

[12] Abiodun A, Aro Sam Agbo Olufemi B, Omole. Factors influencing regular physical exercise among the elderly in residential care facilities in a South African health district. African Journal of Primary Health Care and Family Medicine. 2018; 10(1).

[13] Rivera Torres S, Fahey TD, Rivera MA. Adherence to Exercise Programs in Older Adults: Informative Report. Gerontol Geriatr Med. 2019; 5: 1-10.

[14] Rai R, Jongenelis MI, Jackson B, Newton RU, Pettigrew. Factors influencing physical activity participation among older people with low activity levels. Ageing and Society. 2020; 40(12): 2593-2613.

[15] Lackland DT, Voeks JH. Metabolic Syndrome and Hypertension: Regular Exercise as Part of Lifestyle Management. Current Hypertension Reports. 2014; 16: 492.

[16] Nau T, Nolan G, Smith B. Promoting adherence to organised physical activity among socially disadvantaged older people. Ageing and Society. 2021; 41(2): 421-438.

[17] Lee IM, Shiroma EJ, Lobelo F, Puska P, Blair SN \& Katzmarzyk PT. Lancet Physical Activity Series Working Group. Effect of physical inactivity on major non- communicable diseases worldwide: an analysis of burden of disease and life expectancy. Lancet. 2012; 380(9838): 219-29.

[18] Levinger P, Panisset M, Dunn J. et al. Exercise intervention outdoor project in the community for older people results from the ENJOY Seniors Exercise Park project translation research in the community. BMC Geriatric. 2020; 20: 446.

[19] Martinson BC, O'Connor PJ, Pronk NP. Physical inactivity and short-term all- cause mortality in adults with chronic disease. Erratum in: Arch Intern Med. 2001; 161(9): 1173- 1180.

[20] Boyette LW, Lloyd A, Boyette JE, Watkins E, Furbush L, Dunbar SB, Brandon LJ. Personal characteristics that influence exercise behavior of older adults. J Rehabil Res Dev. 2002; 39(1): 95-103.

[21] Lisa W Boyette, Adriene Liyoyd, James E Boyette, Erica Watkins, Lori Furbush, Sandra B, Dunbar L Jerome Brandon (2002). Journal of Rehabilitation Research and Development. 2002; 39(1): 95-103.

[22] Findorff MJ, Wyman JF, Gross CR. Predictors of long term exercise adherence in a community-based sample of older women. J Womens Health (Larchmt). 2009; 18(11): 1769- 1776.

[23] YS Lee, RN. Gender Differences in Physical Activity and Walking Among Older Adults. Journal of Women \& Aging. 2008; 17(1-2): 55-70.

[24] UKRI. Poorer people are less physically active. Economic and Social Research Council. 2014.

[25] D McArthur, A Dumas, K Woodend, S Beach, D Stacey. Factors influencing adherence to regular exercise in middleaged women: a qualitative study to inform clinical practice. BMC Womens Health. 2014; 14: 49. 